\title{
From the risk culture to the local cultures of risk. An ethnographic investigation of living with a constant flood risk in the South East of France.
}

\author{
Séverine Durand ${ }^{1, a}$ \\ ${ }^{1}$ Pacte - UGA, Cité des territoires, 38000 Grenoble, France
}

\begin{abstract}
In France, flooding is the leading cause of mortality due to natural disasters and cause very significant economic damage. The question of risk forgetting has been identified as one of the key issues to reduce these negative consequences of flooding. There is need to study this oversight of risk on a long term basis, long after the event takes place and when routines are re-established. This is the challenge faced by the ethnographic dissertation summarized in this article: understanding the mechanisms of risk forgetting by investigating how the issue of flooding occurs in everyday life. The dissertation questions what circulates about flooding between inhabitants and how they organize their practices in relation to the risk. The field of study is a french suburban city which was built on wetlands and remains vulnerable to flash floods. This case study provides insight into the collective mechanisms from invisible danger implementation. The increased visibility of the protection made by local policies and the comforting effect of normative sharing provided a normalization of the trust in the protection. Through the interactions, statements are continually developed in the interests of their acceptability: statements of relativism circulate more than the ones that open on the horizon of danger. Moreover, the current development of a logic of safety for social risks reduction contradicts the prevention of flooding. Above all, neither the links between inhabitants nor the links with their living environment provide a sufficient collective development base for a risk culture deployment.
\end{abstract}

\section{Introduction ${ }^{1}$}

In metropolitan France, flooding is the leading cause of mortality due to natural disasters and cause very significant economic damage. The question of risk forgetting has been identified as one of the key issues to reduce these negative consequences of flooding [2]. There is need to study this oversight of risk on a long term basis, long after the event takes place and when routines are re-established. This is the challenge faced by this ethnographic dissertation: understanding the mechanisms of risk forgetting by investigating how the issue of flooding occurs in the lives of people. The methodological framework makes this dissertation original: putting the risk back in a living considered in its entirety, when routine is at work. In order to do this, a resident observation was at the heart of the research system. And it is this attitude that gives all the power to the results of this dissertation, since it allowed a concrete investigation of the living with risk. By adopting a newcoming position in a flood area, I have, myself,

\footnotetext{
1 This article summarized the original results of a dissertation in environmental sociology defended in june 2014 [1]
}

experienced the situation and, with the benefit of a reflective work, I was able to better qualify this experience thanks to the intersection with other investigative materials. This questioning about the living with risk has been re-inscribed in the historical, socioeconomic, and political density of the environment. The research framework has combined the "resident observation" (i.e., an installation in a flood area for four years while meticulously keeping a field journal) to a work on archives (local press, municipal newspaper, urbanism documents, minutes of the municipal councils, records of public inquiries related to flooding, legislation, expert reports, management, documents, etc.); participant observation of the public meetings, town councils and various activities of the municipality; conducting semistructured individual interviews with residents, managers and risk experts (50) as well as group interviews with residents (3 meetings). To investigate the question of the "risk forgetting" the best we could, we chose a field where the last occurrence of a flood was a long time ago. This field of study is Lattes, a suburban city that has seen a recent population explosion, located between the sea and the first ring of the Montpellier conurbation. The model of suburban housing is now dominant and the many assets of the territory (proximity to the city and the

\footnotetext{
a Corresponding author: severine.durand07@gmail.com
} 
sea, proximity to transportation routes, landscaped assets, tranquility) confer substantial property values to this city. This attractiveness is combined with an environmentally vulnerable position, since the city is built on a former swamp, near ponds, and crossed by the Lez River. The latter is subject to flash floods, which are quick to occur and potentially devastating. My dissertation captures the ethnographic study of the case in three steps that are maintained here to present the main results: first, the historical construction of the state of vulnerability (1); second, the nature of the local way of living (2); and third, I finally focus - in a pragmatic perspective - on the meticulous monitoring of all forms of diffusion of the flood thing (3).

\section{From the colonization of a swampy plain to the concrete protection of a popular area ${ }^{2}$}

The human presence at the site of the city of Lattes is very old, and so is the desire to control the lake environment. The ancient port of Lattara and prosperous Gallo-Roman city, Lattes, became a medieval port that allowed the expansion of the city of Montpellier. With the establishment of a river port in Montpellier, Lattes' port activity dwindled [4]. In the early Twentieth century, Lattes was reduced to a small farming town and its inhabitants were called the mosquito eaters [5]. In the early 1960s though, several proactive projects of management stimulated a rapid upheaval. As part of the Racine mission ${ }^{3}$, Languedoc-Roussillon region was cleansed of its mosquitoes in order to attract more tourists. Lattes took advantage of the mosquito cleansing that processed the ponds bordering the city. In a context of urban development, where housing demand was steadily increasing, what was originally an agricultural plain, then began to offer housing areas near Montpellier and the sea. This was followed by rapid urban development. Even when the river burst its banks in 1976 and flooded the first built neighborhood, the building of three years later and the lack of new weather events comforted the confidence in the protection. Paradoxically, it is also to help finance this project than other neighborhoods were opened to construction. Until the early 1990s neighborhoods were being built along the dikes, such as that of Port Ariane and Gardens Piacenza (Figure 1$)^{4}$. More recently (2003), when the possibility of

\footnotetext{
${ }^{2}$ The trajectory planning of the city is presented in more detail in a previous article [3]

The Interministerial Mission of Languedoc-Roussillon coastal planning, called «mission Racine», set up by the Datar (Interministerial Delegation for Spatial Planning and Regional Attractiveness) has, from 1963 to 1983, created the conditions the development of tourism and protection of natural areas on the 240 kilometers of coastline ranging from the Petit Rhône to the Spanish border. Sources: http:/www.languedocroussillon.pref.gouv.fr/actions/missionlittoral/presentation.shtm (accessed 2 June 2007).

${ }^{4} 40 \%$ of the existing city buildings were built between 1975 and 1989 . Between 1980 and 2000, the population was multiplied by 3.5 .
}

the flood was remembered during major rainfall events and threatening Lattes, the risk exposure increased tenfold. The risk of seawall failure considerably increased the hazard, at a time when the land and human stakes of the city were much larger [6], thus providing arguments for new protection works. From 2008 to 2012, Pharaonic protection works (i.e. strengthening of the seawalls and the creation of a flood diverter) were conducted to protect the city. In the current residential population $(18,000)$, very little trace remains of the agricultural population of the 1960s (1 600 inhabitants). With the change of land use and the renewal of associated uses, a drastic change occurred in the profiles of people living in Lattes. There is no need to say that the people living there presently do not adapt (or badly) to the expected flood, as did the agricultural population who saw, in the flood, a fertilizer. Hence, the transition from an agricultural to a suburban area introduced the flood as a "risk". In this urban trajectory, the settlement was directed by local or national intentions ${ }^{5}$, defining relatively homogeneous groups of people. Municipal politics participated in maintaining a relatively homogeneous population, defending a "human scale" urbanism constructed in opposition with an «elsewhere". This opposition has manifested itself in a reluctance to include public housing in the most recent development of the city. Since then, local property values have significantly increased, the entry selection now operates through the financial criteria ${ }^{6}$. While they are typically associated with the flood risk in other risky territories [7], the restrictions on buildability are more associated in Lattes with the will to maintain a certain quality of life. Therefore, around a claim of tranquility in Lattes, there is a will of public safety expressed through other risks; this works on a form of shelving of various figures of otherness. Unlike an identity that would have been built by itself, this form of community has no common experience, it does not really found or unify elements. It was formed by rejecting certain figures that were stigmatized. Here, continuity is based on a chosen sociability.
Sources: Census of Population, National Institute of Statistics and Economic Studies (Insee)1999.

${ }^{5}$ In the early 1960 s though, a part of the city is urbanized to participate in the resettlement of repatriated from Algeria. These returnees, all from two villages (Novi and Zéralda) then formed a fairly close-knit community. Especially, they have changed significantly the distribution of votes in the municipal election. According to the testimonies of the elders of the city, this fact would have encouraged the municipal team to open urbanization of other parts of the city and to reserve access primarily within selected networks to maintain the vote balance in their favor.

${ }^{6}$ Approximatively $60 \%$ of the housing stock is for owners : $59.8 \%$ owners and $36.6 \%$ of tenant (including only $2.9 \%$ in social housing while the French law requires $25 \%$ minimum of social housing in cities). Sources : Census of Population, Insee, 2006. 


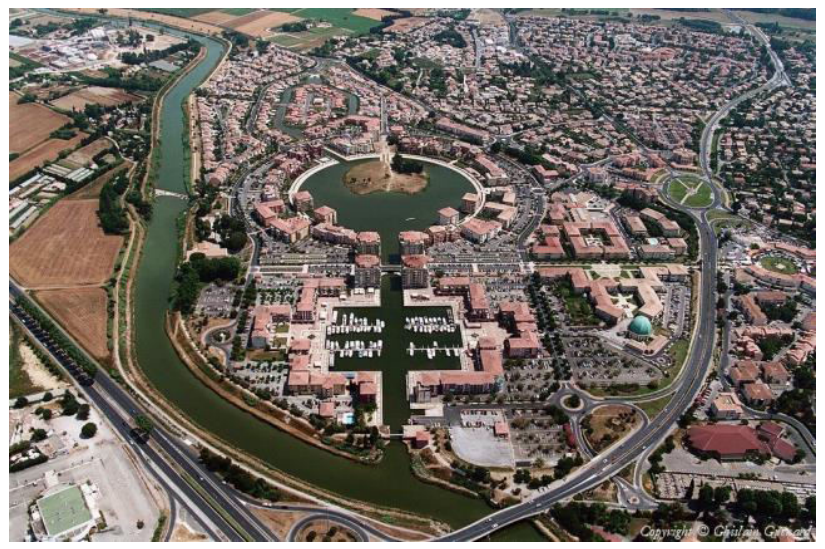

Figure 1 : Aerial view of Port Ariane neighborhood (Ghislain Gurnard ()).

\section{When the mode of living gives assurance but keeps away and exposes}

An analysis of the Lattois way of living reveals a peaceful and comfortable living, but where social relations are marked by distance. In fact, a certain social homogeneity characterizes its inhabitants. The Lattois enjoy a material freedom that challenges the vision of a forced suburban. The accumulation of vulnerability to natural hazards with other types of vulnerabilities, including social and economic ones [8] does not work in Lattes. The area is popular because it has plenty of advantages $^{7}$. These advantages are not counterparties, nor facilitators of omission, but instead are arguments for a living environment that we have to defend against the constraints of nature. If the environment is chosen for the pastoral setting it offers, then the domesticated nature is there to accommodate human activities. The natural area of Mejean, which borders the city, evolves into a park for recreation and relaxation, and the river is dammed in Cycloroute, towards the sea. Nature becomes recreational, a supportive place for fun activities. In this movement, knowledge about the environment is scarce. The overrepresentation of newcomers anchored on the so-called old attached [10], compromises the ability of communication between residents, particularly about the environment and its possible flooding. In addition, the urban choices created an environment where no space is left to chance and where the appropriation of the public space is difficult. Thus, this hyper-development does not leave much room for initiatives to take place outside of the intimate living spaces. Of course social relations are developing, but mainly in the context of professional and recreational activities, and in the spatial proximity between neighbors. The inhabitants all seem to agree about the tranquility of living in Lattes and the response to the need for order and security that this environment paradoxically allows. Furthermore, an important concern,

\footnotetext{
${ }^{7}$ Such observations were made especially for suburban land similarly exposed to flood risk in North America [9] ${ }^{8}$.
}

vis-à-vis the risk of urban insecurity, materializes in the practices of the inhabitants. These practices reflect an operative vigilance that has no equivalent for the risk of flooding. The problem is that this way of living brings a reassuring response, vis-à-vis this safety need, which contradicts the prevention of flooding. The frame of the structure, with its high fence walls, shutters and electric gates, or even its barred windows, constitutes an obstacle for evacuation in case of flooding. It also prevents the development of sociability in spatial proximity. This structural limits the interactions between the inhabitants. And we know that only these interactions would build a sufficient base to the collective elaboration that the deployment of a risk culture demands.

\section{The non-circulation of the possibility of flooding}

This ethnographic study shows that the statements about the flood do not travel (or only very little) in everyday discussions. The paucity of references to the possibility of a flood is the first result of this research. But this lack of reference to flooding does not mean that there is a local unconsciousness about the risk. The invisibility setting cannot be explained by a flood that would not have entered the public issue status [11]. To a large extent, the people are informed about the exposure of the territory to flooding. The topic was a problem but it has since been "settled." In the public space, what is now circulating is the technical possibility of controling the flood that is defended by the local authorities. The protection offered by the building works is the main way in which floods are discussed. Preparing for the possibility of flooding does not appear (or very little) in local concerns. If the weather alert time shows the capacity of people to adjust their behavior, then the long time resident observation reveals the progressive blurring of the preventive behaviors. It also reveals the enforcement under constraint of some regulatory impositions in management crisis for those from whom they are needed (teachers, real estate agents, etc.). The local protection message clouds the prevention avenues. In most alert situations, without denying the existence of vigilance, there is no local appropriation of the danger. In a context of frequency regarding the weather vigilances, it appears difficult to "switch" to an alarmist state when there is no concrete evidence of the need for this alarmism. When the horizon of the danger is not considered, it does not take shape easily. In Lattes, we no longer see the river, but the protection against the river (the seawall), compromises the possibilities of overflowing. Even though the population is properly informed, this information is highly technical and feeds the insurance of the protection. The imagination of the people cannot be fed by any imagery of the flooding, as the flooding has no right of "citizenship" in the official representation of the city. The local political communication frames the circulations that dominate the public space. Representative of the region's engineering tradition $[12]^{11}$, the local political flood management is 
also part of a broader way of doing local politics and is supported by a territory vision, an idea of what progress should be. The current development project of Montpellier Mediterranean Metropole, "on the road for the sea," has encouraged the belief in the potential control of the natural elements, a belief that has been made possible by the faith in ecological modernization [13]. The local authorities claim to be experts and the best qualified to manage the problem: They position themselves as the owners of the problem [14]. The technician position, defended by the local politicians, raises questions in the dialogical exchange with the locals. By resorting to systematic expertise on a subject presented as highly complex and by ensuring that they control the problem, the local politicians do not leave much to the residents. Furthermore, we observe a certain "convergence of interests" between managers and residents on the principle of protection against flooding, and so the residents never really protested against the management policy established. The few remaining protests and the controversies that they raise do not spread to the rest of the population of Lattes. The disqualification of the inhabitants' knowledge, along with the enhancement of scientific knowledge, have defeated the inhabitants' attempts to be involved. In fact, the design of the participatory arrangement forced a reformat of the experential knowledge that emptied them of their meaning. Along with this local protection policy that compromises the thematization of the possibility of flooding, are combined social logics that maintain their absence. The reinforcing effect of the normalization of confidence in the protection amplifies the invisibilitysetting of the danger. To the horizon of the drama, we oppose the possible protection. Multiple forms of relativism are called in the discursive exchange in order to offset the dramatization induced by the formulation of the question. Socially sharing a concern is difficult; if doubts persist, they are shared less than the expression of confidence. Publicly considering the flood in an environment is not an easy task. It is also marked by the possibility of the protection (a possibility which seems to be shared by all). The discursive circulations of the possibility of controlling the natural elements act as inhibitors, that is, as forms of deterrence to the mere reference to the possibility of flooding. In Lattes, the dramatic horizon of flooding does not take shape politically or socially, so there is no (or very little) "circulations" regarding this possibility.

\section{Conclusion}

By offering unique perspectives of analysis, the study case proposed by this dissertation is likely to shed light on a variety of situations. First, this study provides insight into the collectively constructed mechanisms setting the invisibility of danger. The expected risk culture would require that the horizon of the flooding is considered. This analysis shows that the visibility of the protection measures and the comforting effect of sharing normative standards encourage the confidence in the protection, which thereby prevents the formation of a concern about flooding. Second, by putting the issue of risk back in a living considered in its entirety, this study shows how the different components of a territory including risks - are interdependent and deserve to be apprehended together and not separately. The study of the inhabitants' practices has shown that the way of living provides an answer to the need for "security against intrusion" and for the need for intimacy that is opposed to the prevention of flooding. Third, this work complements the sociology of risk and particularly the studies about the risk culture. This case study has shown that even though the local political composition of the problem would not directly prevent the development of a sense of risk, it would still not be enough to call for it. To call for this culture, we must combine a concern for the substrate on which the "risk culture" would develop. In Lattes, we have a sociability marked by a strong social homogeneity, a low investment in the surroundings of the place of intimate life, and a reduction of the proximate social relations. In other words, Lattes offers the panorama of a "dormitory town" where life is quiet, but where the nature of social ties do not form sufficient foundations for a collective development. A culture implies something rooted in a community and held alive by repeated interactions. The result of this study is that nothing like that takes place in Lattes. The reason for this is not that its inhabitants are unaware or that they deny the risk; they simply find no practical support (given the state of the social web and what circulates in this web) to collectively refine an intelligence about flooding. In other words, there is no way for them to manufacture and to maintain together such a risk culture.

\section{References}

1. Durand S. [1]. (2014). «Vivre avec la possibilité d'une inondation?»: Ethnographie de l'habiter en milieu exposé.. et prisé.[dissertation].[Aix-enProvence (FR)]: University of Aix Marseille. 410 p.

2. Picon B., Allard P., Claeys-Mekdade C. and Killian S. (2006). Gestion du risque inondation et changement social dans le delta du Rhône: Les catastrophes de 1856 et 1993-1994. Quae.

3. Durand S. (2015). Du marécage à la zone résidentielle protégée: trajectoire d'une zone inondable. Les annales de la recherche urbaine;110:174-185.

4. Blanchemanche P. (2000) La plaine de Lattes du XIIe au XIXe siècle: Dynamique naturelle et mise en valeur. Lattara, 178.

5. Franck L. (1982). Une rivière nommée Lez. Imprimerie de la Charité, Montpellier.

6. Quévremont P. (2008). Expertise des projets d'actions de prévention des inondations sur le bassin du Lez. Ministère de l'écologie et du développement durable; 2008. Report of the General Inspectorate of Environment.

7. November V., Penelas M. and Viot P. (2008). L'effet Lully: un territoire à l'épreuve d'une inondation. Cosmopolitiques, 17, 89-106.

8. Wisner B., Blake P., Cannon T. and Davis M. (1994). At risk. New York: Routledge. 
9. Davis M. (1999). Ecology of fear. Vintage Books: New York. 484 p.

10.Sencébé Y. (2007). Individualisme de repli sécuritaire ou d'ouverture affinitaire, Les annales de la recherche urbaine, 102, 59-67.

11. Chabal J. (2005). Le risque invisible: La nonémergence d'un problème public. Politix, 2(70), 169195.

12.Vinet F. (2001). Approche institutionnelle et contraintes locales de la gestion du risque. Recherches sur le risque inondation en Languedoc-Roussillon. [HDR dissertation]. [Montpellier (FR)]: University Paul Valery. 210 p.

13. Mol A.P.J. and Sonnenfeld D.A. (2000). Ecological Modernisation Around the World: Perspectives and Critical Debates. London: Routledge.

14. Gusfield J. (1981). The culture of public problems. Drinking-Driving and the Symbolic order. Illinois: The University of Chicago press.

\section{Acknowledgments}

I am grateful to my dissertation advisor Samuel Bordreuil. I also thank the National Research Institute of Science and Technology for Environment and Agriculture for funding this dissertation and its supervising staff A. Richard-Ferroudji and F. Grelot. 